\title{
INVESTIGATION OF THERMAL RESISTANCE OF DEPOSITED METAL DESIGNED FOR RESTORATION OF MILL ROLLS
}

\author{
A.A. BABINETS, I.A. RYABTSEV, I.A. KONDRATIEV, I.I. RYABTSEV and G.N. GORDAN \\ E.O. Paton Electric Welding Institute, NASU
}

11 Bozhenko Str., 03680, Kiev, Ukraine. E-mail: office@paton.kiev.ua

\begin{abstract}
The method of experimental evaluation of thermal resistance of deposited specimens was updated. The new method allows evaluating the nature of propagation of thermal fatigue cracks across the thickness of deposited layer, as well as the effect of deposition of intermediate layers of different composition on thermal resistance of specimens. Using the updated procedure, the investigations of effect of deposition of a plastic sublayer by wire Sv-08A on thermal resistance of specimens, deposited by flux-cored wires PP-Np35V9Kh3GSF and PP-Np-25Kh5FMS, which are most widely used for restoration and strengthening of hot mill steel rolls, were carried out. Hardfacing of the plastic sublayer allowed increasing the general thermal resistance of deposited specimens by 1.2-1.5 times. In addition, it was found that the plastic sublayer arrests the propagation of thermal fatigue cracks into the base metal, thus preventing, to a certain degree, the fracture of the deposited part. 6 Ref., 1 Table, 5 Figures.
\end{abstract}

Keywords: arc hardfacing, hardfacing of mill rolls, multilayer hardfacing, plastic sublayer, thermal resistance, procedure of tests

Thermal resistance or resistance against formation of fire cracks is one of the most important characteristics defining the service life of mill rolls. Thermal fatigue cracks are appeared on the surface of rolls after relatively small numbers of heat changes as a result of effect of cyclic thermal stresses occurring due to non-free changes in sizes of separate regions of the part at cyclic changes of temperature [1-3].

At the present time the steel mill rolls at the majority of metallurgical plants are restored by the methods of hardfacing using materials, which produce the deposited metal of type of heat-resistant and semiheat-resistant tool steels [1]. In this case a plastic sublayer is deposited by wires of $\mathrm{Sv}$-08A type, as a rule, before the working layer deposition.

The preliminary evaluation of thermal resistance of hardfacing materials is carried out by using different laboratory procedures, based mainly on multiple repetition of cycles of heating and cooling of specimens of definite sizes, which is leading, as a result, to cracking of their surface. As a rule, using the existing methods the thermal resistance is evaluated by number of heat-cooling cycles up to appearance of a net of fire cracks $[4,5]$.

Carried out earlier investigations of thermal resistance of deposited metal of 35V9Kh3GSF and 25Kh5FMS type [1], mostly often used for restoration of steel rolls of hot rolling showed that it amounts to 70-200 heat-cooling cycles before the appearance of developed net of thermal cracks. The depth of propagation of these cracks into the deposited layer is usually $0.5-2.5 \mathrm{~mm}$. The further increase in heat-cooling cycles leads only to the fuller opening of cracks, and the crack depth is not almost increased. Thus, at tests using this procedure it is impossible to evaluate the development of thermal fatigue cracks into the depth of deposited layer and effect of sublayer on the nature of development of thermal fatigue cracks. When investigating the thermal resistance of deposited metal it is necessary to account also for structural changes, which can occur in it as a result of cyclic high-temperature effects. Irreversible changes of structure and properties of the deposited metal during service predetermine mainly the serviceability and reliability of the deposited mill rolls.

The aim of this work was to update the methods of investigation of thermal resistance and to study the nature of development of thermal fatigue cracks in multilayer deposited metal. It was also necessary to investigate the structural transformations in deposited metal of selected types as a result of tests of its thermal resistance.

To study the nature of development of thermal fatigue cracks into depth of the deposited layer, the following procedure was developed. From the results of preliminary experiments on thermal resistance a fixed number of heat-cooling cycles, 
Chemical composition and hardness of deposited metal

\begin{tabular}{|c|c|c|c|c|c|c|c|c|}
\hline \multirow{2}{*}{ Type of deposited metal } & \multicolumn{7}{|c|}{ Content of alloying elements, wt.\% } & \multirow{2}{*}{ Hardness $H R C$} \\
\hline & $\mathrm{C}$ & $\mathrm{Si}$ & Mn & $\mathrm{Cr}$ & $\mathrm{W}$ & $\mathrm{V}$ & Mo & \\
\hline PP-Np-35V9Kh3GSF (without sublayer) & 0.34 & 0.74 & 0.60 & 3 & 9.30 & 0.43 & - & $51-53$ \\
\hline PP-Np-35V9Kh3GSF + Sv-08A sublayer & 0.32 & 0.70 & 0.56 & 2.84 & 9.06 & 0.40 & - & $49-51$ \\
\hline PP-Np-25Kh5FMS (without sublayer) & 0.26 & 0.79 & 0.64 & 5.50 & - & 0.40 & 1.01 & $49-51$ \\
\hline PP-Np-25Kh5FMS + Sv-08A sublayer & 0.26 & 0.76 & 0.64 & 5.40 & - & 0.40 & 0.99 & $48-50$ \\
\hline
\end{tabular}

equal to 200, was selected. This guaranteed the appearance of a developed net of fire cracks on the surface of test specimens, and then the deposited surface of the specimen was grinded until their full removal. Here, the thickness of grinded layer of deposited metal was recorded, and then the specimen was subjected to repeated thermal cycling at the same number of cycles. Operations of thermal cycling and grinding are repeated up to reaching the minimum possible thickness of a wear-resistant layer, equal to $1.5-2.0 \mathrm{~mm}$. Further, the specimen was cut in spot of heating, and the depth and nature of propagation of thermal fatigue crack were investigated on a macrosection.

This procedure was used in investigation of thermal fatigue crack development in metal deposited by flux-cored wires PP-Np-35V9Kh3GSF and PP-Np-25Kh5FMS without and with sublayer, deposited by solid wire Sv-08A. Steel $40 \mathrm{Kh}$ was used as a base metal. Semi-products for next manufacture of specimens for thermal resistance testing were deposited by two schemes:

- deposition by wire 35V9Kh3GSF or 25Kh5FMS in four layers without sublayer;

- deposition of sublayer by wire Sv-08A in two layers and next two-layer deposition by the wire $35 \mathrm{~V} 9 \mathrm{Kh} 3 \mathrm{GSF}$ or $25 \mathrm{Kh} 5 \mathrm{FMS}$.

After deposition the semi-products were subjected to delayed cooling under the flux layer. Total thickness of deposited layer in all the cases was about the same and amounted approximately to $10 \mathrm{~mm}$. Chemical composition of metal, deposited by wires 35V9Kh3GSF and 25Kh5FMS, is given in the Table. Specimens of $40 \times 40 \times$ $\times 40 \mathrm{~mm}$ size were cut out from semi-products for investigation of thermal resistance of deposited metal. Deposited surface of specimens was subjected to grinding.

Using the updated procedure, the investigation of thermal resistance of specimens was carried out in unitized-modular installation for testing different properties of the deposited metal [5]. The deposited surface of specimens was heated periodically by a gas cutter up to $800{ }^{\circ} \mathrm{C}$ for $11 \mathrm{~s}$ (diameter of heat spot was about $15 \mathrm{~mm}$ ), and then it was cooled by running water down to $70-80{ }^{\circ} \mathrm{C}$ for $8 \mathrm{~s}$.

For specimen, deposited by wire 35V9Kh3GSF without sublayer, a strongly developed net of fire was typical (Figure 1, $a$ ). After 200 heat-cooling cycles the regrinding was made until full removal of the crack net. In total, 800 cycles and three regrindings of specimens were made, the removal of metal during each of them was $1.3-1.8 \mathrm{~mm}$. When the thickness of metal reached about $2 \mathrm{~mm}$, the tests were interrupted, the specimen was cut out and macrosection was manufactured. Figure 2, $a$ shows how the largest crack is transferred from the deposited metal into base one.

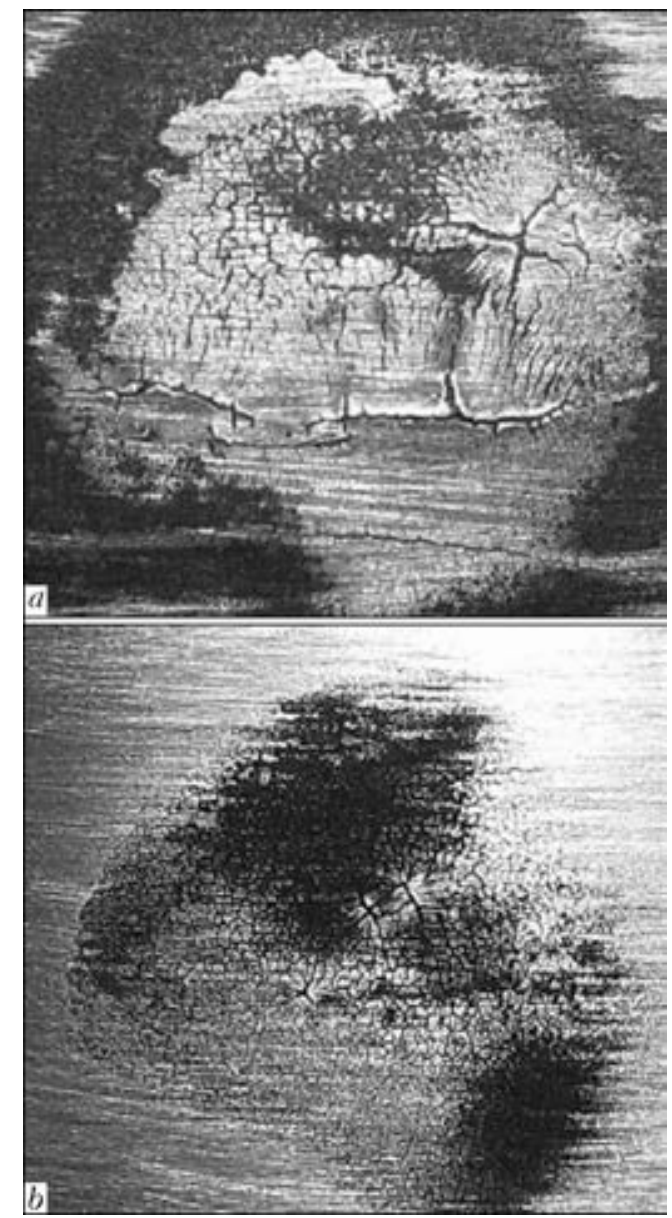

Figure 1. Appearance of surface of specimens deposited by flux-cored wire PP-Np-35V9Kh3GSF without $(a)$ and with Sv-08A sublayer (b) after thermal tests 


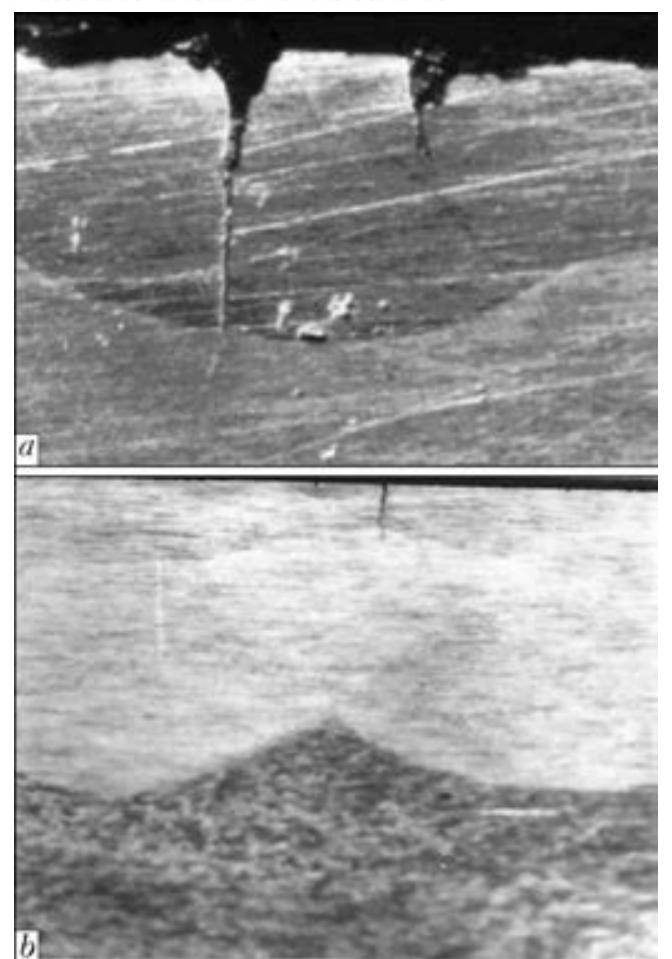

Figure 2. Cross macrosections section of specimens deposited by flux-cored wire PP-Np-35V9Kh3GSF without $(a)$ and with Sv-08A sublayer (b) after thermal tests

In specimen, deposited by wire 35V9Kh3GSF along Sv-08A sublayer, the much less expressed net of cracks was observed (Figure 1, b), their depth was smaller. This influenced on value of metal removal for each regrinding, it was $0.4-$ $1.1 \mathrm{~mm}$. Probably, the deposition of plastic sublayer has led to reduction of residual hardfacing stresses in a working layer, and its thermal resistance increased [6]. Taking into account the smaller single removal of damaged metal, the

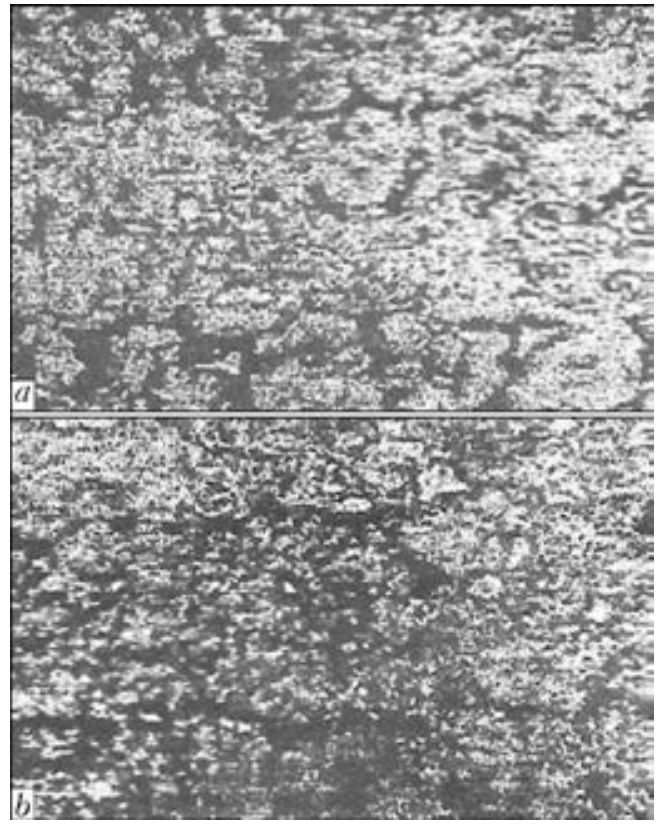

Figure 3. Microstructure $(\times 400)$ of 35V9Kh3GSF deposited metal before $(a)$ and after $(b)$ thermal tests total number of heat-cooling cycles was increased to 1200 , i.e. by 1.5 times, as compared with that in specimen without sublayer. After reaching the minimum possible thickness of wear-resistant layer the specimen was cut out, and macrosection was manufactured (Figure 2, b). It is seen clearly that the crack is passed through the wear-resistant layer and arrested in a low-carbon sublayer.

Similar results were obtained in testing specimens, deposited by flux-cored wire 25Kh5FMS without and with a sublayer, deposited by wire $\mathrm{Sv}$-08A. The only difference, i.e. the higher thermal resistance of deposited metal 25Kh5FMS [1], has led to the fact that removal of metal after each 200 heat-cooling cycles was relatively small, thus resulting in significant increase of total cycles of tests. Also, in this case the deposition of sublayer has led to the increase of thermal resistance of the deposited working layer. In hardfacing without sublayer the total number of heat-cooling cycles was 2000, and metal removal after each 200 cycles was $0.4-0.6 \mathrm{~mm}$. In hardfacing with Sv-08A sublayer the thickness of asgrinded layer after each 200 cycles of tests was about $0.2-0.3 \mathrm{~mm}$. Taking into account the small removal of material after each cycle of testing, it was managed to perform 2400 cycles of tests on this specimen, i.e. by 1.2 times more than on specimen without sublayer.

Thus, it can be considered that the hardfacing of $\mathrm{Sv}-08 \mathrm{~A}$ sublayer allows increasing the general thermal resistance of specimens, deposited by wires 35V9Kh3GSF and 25Kh5FMS, by 1.2-1.5 times.

The nature of crack propagation in 25Kh5FMS deposited metal was similar to the nature of propagation of cracks in 35V9Kh3GSF deposited metal. In hardfacing without sublayer the thermal fatigue cracks transferred into the base metal, and in hardfacing with a plastic sublayer the cracks were arrested in this layer. Microstructure of deposited metal of type 35V9Kh3GSF and 25Kh5FMS was examined before and after thermal tests. Microstructure of metal after hardfacing was examined in a last deposited layer, while after thermal resistance tests it was examined in the zone of thermal cycling (location of thermal cracks) at the distance of about 10-20 $\mu \mathrm{m}$ from the deposited layer surface.

Microstructure of 35V9Kh3GSF deposited layer before and after tests is shown in Figure 3. Metal 35V9Kh3GSF has a martensitic structure with microhardness $H V 5140 \mathrm{MPa}$ directly after deposition, and precipitations of residual austenite and negligible amount of eutectics were revealed along the boundaries of polygonization 
(Figure 3, $a$ ). After thermal tests the decay of martensitic component $(H V 3090 \mathrm{MPa})$ was noted, here the small regions of residual austenite were retained (Figure $3, b$ ).

Microstructure of 25Kh5FMS deposited metal was also examined before and after thermal tests (Figure 4). It was found that the structure of deposited metal directly after hardfacing represents a fine-acicular martensite-bainite mixture ( $H V$ 3860-4120 MPa), the polygonization boundaries are not clearly formed. In sites of their formation the precipitations of carbide eutectics are observed (Figure 4, $a$ ).

After tests on thermal resistance the structural changes were occurred in deposited metal of type 25Kh5FMS, proving about coagulation and spheroidization of carbides (Figure $4, b$ ). Decay of martensite and also partial decay of eutectics along the boundaries of polygonization took place, thus leading to the decrease in microhardness of matrix of deposited metal to $H V 2210 \mathrm{MPa}$.

Examination of microstructure showed that as result of multiple thermal cycling the structural changes occur in surface layer of deposited metal of both types, leading to its softening. This was also confirmed by X-ray diffraction analysis. For example, after thermal cycling the content of $\alpha$-phase was increased from 84 up to $87 \%$ in metal of type $35 \mathrm{~V} 9 \mathrm{Kh} 3 \mathrm{GSF}$ due to appearance of ferrite component. In this case the compression stresses of the II kind increased from 0.27 up to $0.44 \mathrm{GPa}$.

The X-ray spectrum microanalysis was made in Camebax SX50 analyzer for study of distribution of main alloying elements in structure of deposited specimens before and after thermal tests at the depth up to $20 \mu \mathrm{m}$ from the surface, parallel to deposit, in automatic mode at interval of $2-99 \mu \mathrm{m}$ along the front of fire crack net. Figure 5 gives results of examinations of deposited metal of type 35V9Kh3GSF. Distribution of main alloying elements in the deposited metal was almost uniform (Figure 5, $a$ ) and remained almost the same after thermal tests, except one moment, namely fatigue crack zone the abrupt decrease in content of alloying elements ( $\mathrm{Fi}^{-}$ gure $5, b$ ) was observed, probably due to their oxidation.

Thus, as a result of multiple heating and cooling the diffusion of main alloying elements was not revealed in surface layer of deposited metal of die steel type, but changes in structure were observed, leading to softening of the deposited metal.

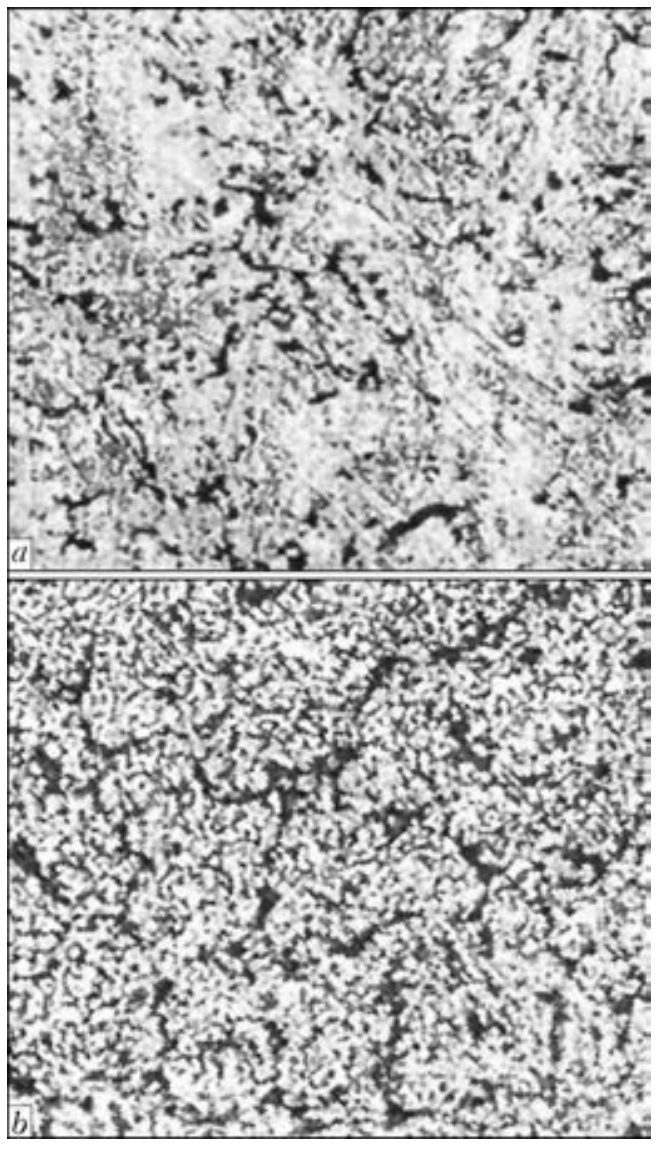

Figure 4. Microstructure $(\times 400)$ of 25Kh5FMS deposited metal before $(a)$ and after $(b)$ thermal tests

The carried out investigations showed the positive effect of a plastic sublayer on thermal resistance of deposited metal of type $35 \mathrm{~V} 9 \mathrm{Kh} 3 \mathrm{GSF}$ and $25 \mathrm{Kh} 5 \mathrm{FMS}$. Owing to more favorable distribution of residual stresses, the thermal resistance of deposited working layer not only increased in hardfacing, but a plastic sublayer arrests also the propagation of cracks $\mathrm{W}, \% \mathrm{Cr}, \% \mathrm{~V}, \%$
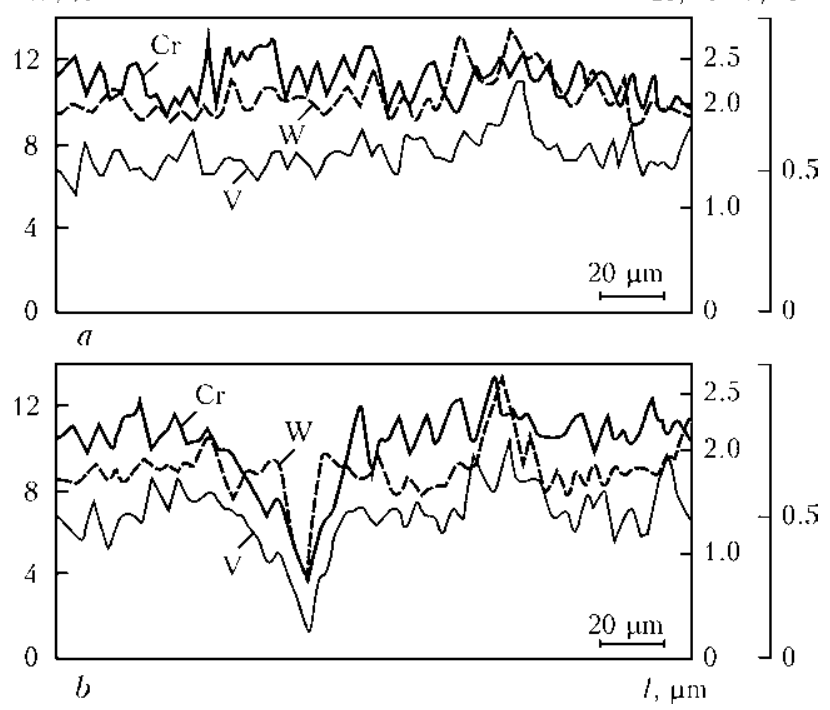

Figure 5. Distribution of main alloying elements in 35V9Kh3GSF deposited metal before $(a)$ and after $(b)$ thermal tests 
into the base metal preventing, to a certain degree, the fracture of the deposited part.

\section{Conclusions}

1. The method of experimental evaluation of thermal resistance of deposited specimens was updated. The new method allows evaluating the nature of propagation of thermal fatigue cracks across the thickness of deposited layer, as well as the effect of deposition of intermediate layers of different composition of thermal resistance of specimens.

2. Using the updated procedure the investigations of effect of deposition of a plastic sublayer by wire Sv-08A on thermal resistance of specimens, deposited by flux-cored wires PP-Np35V9Kh3GSF and PP-Np-25Kh5FMS, which are used for restoration and strengthening of hot mill steel rolls, were carried out. Deposition of the plastic sublayer allowed increasing the general thermal resistance of deposited specimens by $1.2-$
1.5 times. In addition, it was found that the plastic sublayer arrests the propagation of thermal fatigue cracks into the base metal, thus preventing, to a certain degree, the fracture of the deposited part.

1. Ryabtsev, I.A., Kondratiev, I.A. (1999) Mechanized hardfacing of metallurgical equipment. Kiev: Ekotekhnologiya.

2. Dulnev, P.A., Kotov, P.I. (1980) Thermal fatigue of metals. Moscow: Mashinostroenie.

3. Balandin, Yu.F. (1967) Thermal fatigue of metals in ship power machine building. Leningrad: Sudostroenie.

4. Tylkin, M.A. (1971) Increase in service life of metallurgical equipment parts. Moscow: Metallurgiya.

5. Ryabtsev, I.I., Chernyak, P.F., Osin, V.V. (2004) Block-module unit for deposited metal tests. Svarshchik, 1, 18-20.

6. Senchenkov, I.K., Chervinko, O.P., Ryabtsev, I.A. (2013) Numerical modeling of stress-strain and microstructural state of hot roll during multilayer hardfacing and service. In: Mathematical problems of technical mechanics: Transact., Issue 2(22), 139-144.

Received 05.02.2014 